\title{
Analisis Kekerasan Hasil Pengelasan Gas Tungsten Arc Welding pada Baja ST 37 dengan Variasi Media Pendingin
}

\author{
Gede Agus Widiantara*, I Nyoman Pasek Nugraha, Kadek Rihendra Dantes \\ Progam Studi Pendidikan Teknik Mesin, Fakultas Teknik dan Kejuruan, \\ Universitas Pendidikan Ganesha, Singaraja, Bali, Indonesia \\ *Penulis korespondensi: gedeagus2915@gmail.com
}

Histori artikel: diserahkan 09 Juli 2021, direviu 02 Agustus 2021, direvisi 10 September 2021

\section{ABSTRACT}

\begin{abstract}
Cooling media is a substance that increases the hardness value of a material through a heat-treatment process. This study aims to determine the effect of cooling media on the hardness of ST 37 steel due to Gas Tungsten Arc Welding (GTAW). The independent variables, namely water cooling media, seawater cooling media, and oil cooling media, while the dependent variable is the hardness. The specimens using water cooling media, the hardness in the weld area is $47.19 \mathrm{~kg} / \mathrm{mm}^{2}$, in the $H A Z$ area the it is $54.6 \mathrm{~kg} / \mathrm{mm}^{2}$, and the base metal gets a value of $40.87 \mathrm{~kg} / \mathrm{mm}^{2}$. While the specimens with seawater cooling media get a value in the weld area of $76.37 \mathrm{~kg} / \mathrm{mm}^{2}$, in the HAZ area it gets a value of $83.89 \mathrm{~kg} / \mathrm{mm}^{2}$ and the base metal gets a value of $70.13 \mathrm{~kg} / \mathrm{mm}^{2}$. The specimens with oil cooling media the value in the weld area is $40.77 \mathrm{~kg} / \mathrm{mm}^{2}$, in the HAZ area it gets a value of $43.32 \mathrm{~kg} / \mathrm{mm}^{2}$ and the base metal gets a value of $36.09 \mathrm{~kg} / \mathrm{mm}^{2}$. From the hardness values obtained, specimens immersed in seawater cooling media have the higher hardness values compared than water and oil cooling media.
\end{abstract}

Keywords: Cooling Media, Hardness, ST 37

DOI : https://doi.org/10.18196/jqt.v3i1.12245

WEB : https://journal.umy.ac.id/index.php/qt/article/view/12245

\section{PENDAHULUAN}

Baja karbon sedang adalah salah satu logam yang banyak dipakai dalam membuat komponen-komponen mesin yang memiliki kekuatan sedang contohnya adalah roda gigi ataupun poros. Kandungan baja karbon sedang, memiliki kemudahan untuk dikerjakan dengan menggunakan perkakas dan mampu untuk dibentuk sesuai dengan keinginan serta kebutuhan, karena sifat dari baja tersebut yang lunak dan ulet. Kandungan dari baja karbon tersebut sebesar 0,3\%-0,6\%. Beradasarkan kandungannya tersebut baja karbon sedang menjadi pilihan untuk dijadikan sebagai bahan baku komponen mesin, namun karena memiliki kandungan karbon dibawah 0,6\% maka baja karbon sedang harus diberikan perlakuan panas (heat treatment) agar mendapatkan sifat yang sesuai dengan kegunaannya seperti keras dan lunak. Proses perlakuan panas pada umumnya dibagi menjadi proses tempering, carburizing, annealing, dan hardening. Penelitian ini berfokus dengan proses pengerasan (hardening) lebih tepatnya dengan mencelupkan material yang telah diberikan perlakuan panas ke dalam air, air laut, dan oli secara cepat. Teknik quenching merupakan proses pengerasan baja dengan laju pendinginannya yang cepat, dengan tujuan mendapatkan sifat yang lebih keras dari baja tersebut.

Proses pendinginan merupakan salah satu cara untuk meningkatkan dan juga memperbaiki sifat mekanik pada suatu material pada saat proses pengelasan untuk mendapatkan sifat yang sesuai kebutuhan bergantung juga pada pemilihan media pendingin yang tepat, sehingga bisa mendapatkan struktur martensite yang bagus. Hal tersebut terjadi karena apabila unsur karbon yang terperangkap dalam jumlah yang banyak, begitu pula dengan unsur martensite yang terbentuk akan banyak. Hal inilah yang menjadi penyebab nilai kekerasan 
meningkat pada suatu material. Baja karbon merupakan material yang memiliki sifat mampu las yang cukup bagus. Sifat kuat dan keras yang dimiliki oleh baja karbon ini menjadi alasan dipilihnya dalam penelitian ini. Terdapat perubahan sifat mekanik dan sifat fisik dengan baja karbon setelah dilakukannya pengelasan, dengan begitu diperlukan pendinginan yang beragam. Dengan tujuan dapat menghasilkan kekerasan yang sempurna dan maksimal.

Media yang digunakan memberikan pengaruh terhadap proses laju pendinginan dalam menghasilkan struktur martensite hasil transformasi dari struktur austenite. Struktur martensite menjadi penentu seberapa besar sifat mekanik suatu material tersebut meningkat akibat dari diberlakukannya perlakuan panas. Media pendingin selain memberikan pengaruh pada sifat fisis, juga dapat memberikan pengaruh pada sifat mekanis. Pada penelitian yang dilakukan oleh (Darma et al., 2017) yang berjudul Pengaruh Variasi Media Pendingin Terhadap Sifat Mekanik Hasil Pengelasan Material ST 37. Hasil Penelitian menunjukkan hasil pengujian kekerasan dengan media pendingin udara memiliki nilai kekerasan $46,42 \mathrm{~kg} / \mathrm{mm}^{2}$, sedangkan untuk hasil kekerasan pada media pendingin air laut memiliki hasil sebesar 43,98 $\mathrm{kg} / \mathrm{mm}^{2}$, dan untuk hasil pengujian pada media pendingin oli memiliki hasil sebesar 35,32 $\mathrm{kg} / \mathrm{mm}^{2}$. Nilai kekerasan dengan media pendingin udara lebih besar dibandingkan dengan penggunaan media pendinginan air laut dan oli.

Penelitian terdahulu tentang nilai kekerasan material ST 37 dengan memberikan variasi arus dengan menggunakan pengelasan berjenis Gas Tungsten Arc Welding (GTAW) sudah dilakukan oleh (Kolo dan Widayana, 2017) Dari pengujian tersebut diperoleh nilai uji kekerasan pada daerah las pada kuat arus 90 ampere mendapatkan hasil pengujian dengan nilai $68,39 \mathrm{~kg} / \mathrm{mm}^{2}$, pada kuat arus 110 ampere mendapatkan hasil hasil pengujian dengan nilai $87,44 \mathrm{~kg} / \mathrm{mm}^{2}$, dan pada kuat arus 130 ampere mendapatkan hasil pengujian dengan nilai $74,93 \mathrm{~kg} / \mathrm{mm}^{2}$.

\section{METODE}

Pada peneliti ini memberikan variasi media pendingin terhadap material yang sebelumnya sudah diberikan perlakuan panas dengan proses pengelasan menggunakan pengelasan Gas Tungsten Arc Welding (GTAW). Hal tersebut dilakukan guna meningkatkan nilai kekerasan dari material baja ST 37. Variasi media pendingin yang digunakan adalah air, air laut, dan oli. Setelah dilakukan perlakuan panas dan dicelupkan pada media pendingin dengan menggunakan teknik celup cepat (quenching) lalu dilakukan pengujian kekerasan vikcers pada tiga daerah pengujian yaitu pada daerah las, daerah HAZ (Heat Affected Zone), dan logam induk (Nurisna dan Setiawan, 2020). Pengujian ini dilakukan untuk mengetahui nailai kekerasan dari material ST 37 setelah diberikan perlakuan panas dan mendapat variasi media pendingin yang berbeda. Teknik analisa data kuantitatif digunakan pada penelitian ini yaitu untuk mengetahui apakah terdapat perbedaan nilai kekerasan pada material ST 37 dengan memvariasikan media pendinginan air, air laut, dan oli. Dalam penelitian ini metode analisis data yang digunakan adalah ANOVA untuk menguji hipotesis pada penelitian ini.

\section{HASIL DAN PEMBAHASAN}

\section{Hasil Uji Vickers}

Uji kekerasan digunakan untuk menghitung nilai kekerasan dari material setelah diberikannya perlakuan panas dan pemberian variasi media pendingin. Dalam pengujian kekerasan dibagi menjadi 3 jenis yang dibedakan melalui media pendingin pada poses perlakuan panas yaitu, media pendingin air, air laut,dan oli. Jumlah spesimen pada setiap media pendingin berjumlah 5 spesimen sehingga total spesimen terdapat 15 buah yang akan diuji kekerasn Vickers. Setelah penulis melakukan proses pengambilan data pada mesin uji kekerasan vickers dan diperoleh data hasil penelitian dari kekerasan material ST 37 sebanyak 45 kali pengulangan (Tabel 1). Dari hasil tersebut didapatkan data rata-rata untuk setiap variasi media pendingin yang ditunjukkan oleh Gambar 1. 
TABEL 1. Data uji kekerasan vickers pada media pendingin air, air laut, dan oli

\begin{tabular}{|c|c|c|c|c|c|c|c|c|c|}
\hline \multirow[b]{2}{*}{ Spesimen } & \multicolumn{3}{|c|}{ Air } & \multicolumn{3}{|c|}{ Air Laut } & \multicolumn{3}{|c|}{ Oli } \\
\hline & $\begin{array}{c}\text { Daerah } \\
\text { Las } \\
\left(\mathrm{kg} / \mathrm{mm}^{2}\right) \\
\end{array}$ & $\begin{array}{c}\text { Daerah } \\
\text { HAZ } \\
\left(\mathrm{kg} / \mathrm{mm}^{2}\right) \\
\end{array}$ & $\begin{array}{c}\text { Logam } \\
\text { Induk } \\
\left(\mathrm{kg} / \mathrm{mm}^{2}\right) \\
\end{array}$ & $\begin{array}{c}\text { Daerah } \\
\text { Las } \\
\left(\mathrm{kg} / \mathrm{mm}^{2}\right) \\
\end{array}$ & $\begin{array}{c}\text { Daerah } \\
\text { HAZ } \\
\left(\mathrm{kg} / \mathrm{mm}^{2}\right) \\
\end{array}$ & $\begin{array}{c}\text { Logam } \\
\text { Induk } \\
\left(\mathrm{kg} / \mathrm{mm}^{2}\right) \\
\end{array}$ & $\begin{array}{c}\text { Daerah } \\
\text { Las } \\
\left(\mathrm{kg} / \mathrm{mm}^{2}\right) \\
\end{array}$ & $\begin{array}{c}\text { Daerah } \\
\text { HAZ } \\
\left(\mathrm{kg} / \mathrm{mm}^{2}\right) \\
\end{array}$ & $\begin{array}{c}\text { Logam } \\
\text { Induk } \\
\left(\mathrm{kg} / \mathrm{mm}^{2}\right) \\
\end{array}$ \\
\hline 1 & 53,27 & 59,23 & 40,12 & 84,27 & 91,78 & 74,16 & 42,62 & 55,17 & 35,79 \\
\hline 2 & 43,93 & 61,39 & 42,62 & 80,60 & 87,86 & 77,25 & 40,12 & 38,94 & 35,79 \\
\hline 3 & 43,93 & 45,33 & 41,38 & 68,67 & 71,30 & 63,71 & 43,93 & 45,33 & 40,12 \\
\hline 4 & 43,36 & 49,83 & 41,30 & 74,16 & 84,24 & 61,40 & 41,38 & 41,38 & 35,80 \\
\hline 5 & 51,5 & 57,22 & 38,95 & 74,18 & 84,27 & 74,16 & 35,80 & 35,79 & 32,98 \\
\hline Rata-rata & 47,19 & 54,62 & 40,87 & 76,37 & 83,89 & 70,13 & 40,77 & 43,32 & 36,09 \\
\hline
\end{tabular}

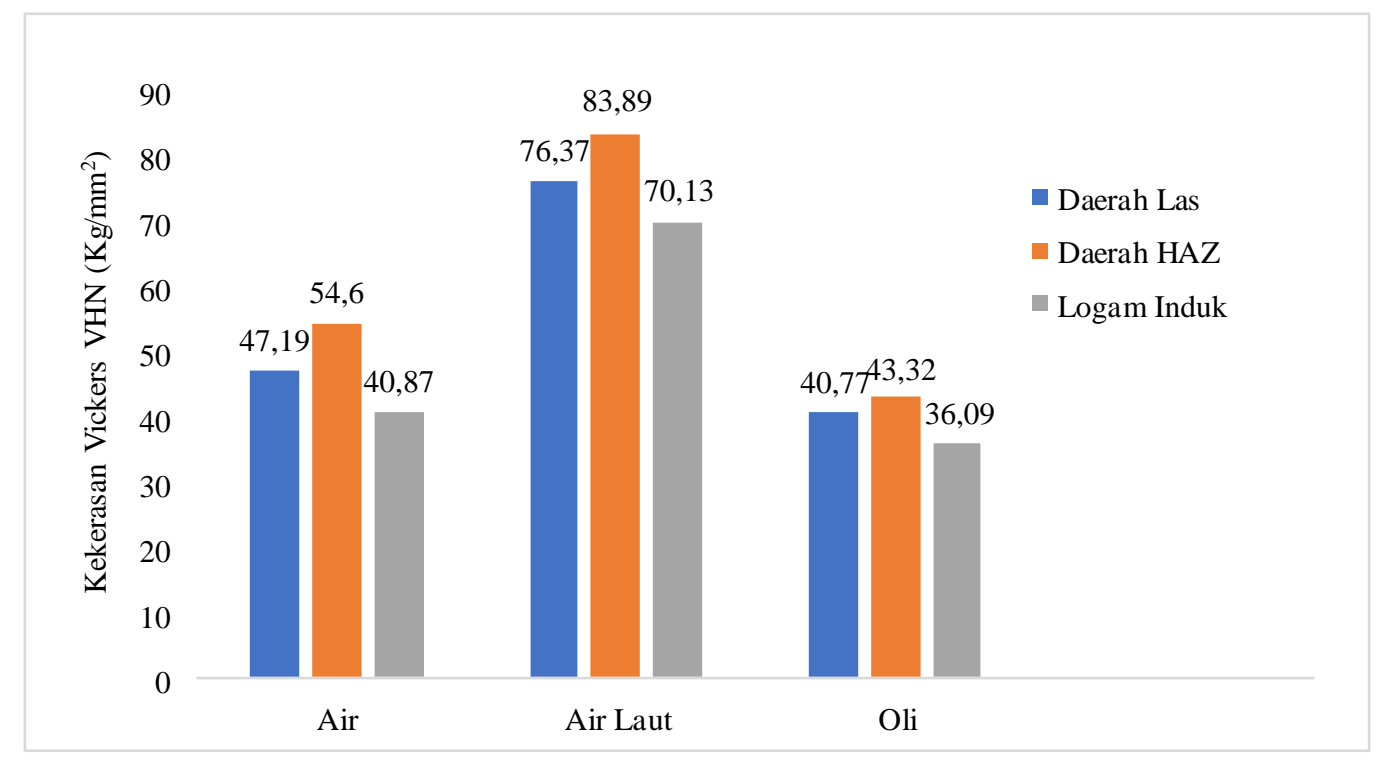

GAMBAR 1. Grafik rata-rata hasil uji kekerasan pada media pendingin air, air laut, dan oli.

Berdasarkan data Tabel 1, hasil pengujian menyatakan bahwa spesimen yang dicelupkan pada media pendingin air laut memiliki nilai kekerasan paling tinggi dibandingkan dengan media pendingin air dan media pendingin oli. Hasil ini selaras dengan penelitian yang dilakukan oleh (Imawan, 2017) yang berjudul "Pengaruh Variasi Pendinginan Pada Proses Quenching Terhadap Nilai Kekerasan, Struktur Mikro Dan Ketangguhan Hasil Pengecoran Aluminum Limbah Piston" pada penelitian ini menggunakan variasi media pendingin air laut, oli SAE 20 dan raw material. Dari hasil pengujian kekerasan dinyatakan bahwa spesimen yang dicelupkan pada media pendingin air laut memiliki nilai kekerasan paling tinggi dibandingkan dengan media pendingin SAE 20 dan media pendingin raw material.

Purwohandoyo, 2018) melakukan penelitian tentang Pengaruh Variasi Media Pendingin Air
Laut, Air Sumur, dan Oli SAE 40 Terhadap Sifat Fisis dan Kekerasan Hasil Pengecoran Kuningan $(\mathrm{CuZn})$ menggunakan Cetakan Pasir $\mathrm{CO}_{2}$. Dari hasil uji kekerasan mendapatkan hasil paling keras pada spesimen dengan media pendingin air laut dengan nilai sebesar 33,94 $\mathrm{HB}_{\mathrm{R}}$, pada spesimen menggunakan media pendingin air sumur mendapatkan nilai sebesar $28,31 \mathrm{HB}_{\mathrm{R}}$, dan pada spesimen dengan media pendingin oli SAE 40 mendapatkan nilai sebesar 27,98 $\mathrm{HB}_{\mathrm{R}}$.

Pada penelitian ini, material yang dicelupkan pada media pendingin air laut mendapatkan hasil kekerasan tertinggi. Hal ini disebabkan karena laurutan garam atau dalam bahasa kimianya memiliki rumus $\mathrm{NaCl}$ (natrium klorida) dengan senyawa ionic terdiri dari ion negatif (anion) dan ion positif (kation). Dengan senyawa tersebut air laut mampu digunakan sebagai salah satu pendingin pada metode perlakuan panas dengan tujuan dapat 
meningkatkan sifat keras suatu material, air laut memiliki sifat pendinginan yang cepat dan baik. Material yang direndam dalam air laut akan menyebabkan benda menjadi keras pada permukaannya, hal tersebut terjadi karena air laut mampu mengikat zat arang. Bahan yang didinginkan dalam larutan garam akan mengakibatkan benda menjadi keras pada permukaan benda, karena dapat mengikat zat arang. Setiap media pendingin memiliki sifat mendinginkan yang berbeda, hal tersebut disebabkan oleh temperatur, viskositas, bahan dasar, dan kadar larutan dari pendingin tersebut perbedaan kemampuan media pendingin disebabkan oleh termperatur, kekentalan, kadar larutan dan bahan dasar media pendingin. Media pendingin memiliki sifat dalam menyerap panas yang berbeda-beda yag dapat berdampak pada hasil kekerasan. Apabila laju pendinginannya cepat maka nilai kekerasan akan semakin baik. Hasil pengujian di atas menjadi bukti bahwa spesimen yang dicelupkan pada air laut memiliki nilai kekerasan yang paling tinggi dibandingkan dengan spesimen lainnya.

\section{KESIMPULAN}

Berdasarkan dari hasil yang diperoleh dan melakukan pengolahan data tentang Pengaruh Variasi Media Pendingin Terhadap Hasil Pengelasan GTAW (Gas Tungsten Arc Welding) Pada Baja ST 37 maka dapat disimpulkan , bahwa terdapatpengaruh variasi media pendingin terhadap hasil uji kekerasan Vickers pada baja ST 37 dimana spesimen yang dicelupkan pada media pendingin air laut mendapatkan hasil uji kekerasan paling tinggi dibandingkan spesimen dengan media pendingin air dan oli.

\section{DAFTAR PUSTAKA}

Purwohandoyo, D. A. 2018. Pengaruh Variasi Media Pendingin (Air Laut, Air Sumur dan Oli Sae 40) terhadap Sifat Fisis Dan Kekerasan Hasil Pengecoran Kuningan (CuZn) Menggunakan Cetakan Pasir CO2. (Diploma thesis, Universitas Muhammadiyah Surakarta).

Darma, K. B. S., Widayana, G., \& Nugraha, I. N. P. 2017. Pengaruh Media Pendinginan Terhadap Sifat Mekanik Hasil Pengelasan Material ST 37. Jurnal Pendidikan Teknik Mesin Undiksha, 5(1).

Imawan, D. 2017. Pengaruh Variasi Pendinginan pada Proses Quenching terhadap Nilai Kekerasan, Struktur Mikro dan Ketangguhan Hasil Pengecoran Aluminium Limbah Piston. (Skripsi, Universitas Negeri Semarang).

Kolo, J. M., Nugraha, I. N. P., \& Widayana, G. 2017. Pengaruh Variasi Arus terhadap Kekuatan Impact dan Kekerasan Material ST 37 Menggunakan Proses Pengelasn Gas Tungsten Arc Welding (GTAW). Jurnal Pendidikan Teknik Mesin Undiksha, 5(2).

Nurisna, Z., \& Setiawan, E. 2020. Pengaruh Filler Pada Pengelasan Tig Baja Karbon dan Stainless Steel 316L terhadap Sifat Mekanik. Quantum Teknika: Jurnal Teknik Mesin Terapan, 1(2), 95-99. 